\title{
ANALISIS KUALITAS AIR TANAH DI SEKITAR TEMPAT PEMBUANGAN SAMPAH MAKBON
}

\author{
Della Natasya Putri \\ Program Studi Teknik Sipil Universitas Muhammadiyah Sorong \\ Jalan Pendidikan No 27 Kota Sorong, Propinsi Papua Barat \\ Email : serlymarlina723@gmail.com
}

\begin{abstract}
ABSTRAK
Air merupakan salah satu kekayaan alam yang paling sering digunakan makhluk hidup untuk kehidupan sehari-hari. Sumber air yang digunakan bisa berasal dari sumur gali, PAM dan sumur pompa. Kualitas dari sumber air yang digunakan harus sesuai dengan baku mutu yang yang telah ditentukan. Tujuan penelitian ini untuk mengetahui kualitas air tanah masyarakat di sekitar TPA sampah Kelurahan Makbon Kota Sorong. Variabel dalam penelitian ini adalah kualitas air tanah yang terdiri dari kualitas fisik. Penentuan variabel fisik dilakukan berdasarkan uji laboratorium dan observasi. Dampak yang ditimbulkan dari kualitas air yang tidak memenuhi baku mutu air bersih adalah terjadinya berbagai penyakit. Bahaya langsung terhadap kesehatan manusia/masyarakat dapat terjadi akibat mengkonsumsi air yang tercemar atau air dengan kualitas yang buruk, baik secara langsung diminum atau melalui makanan, dan akibat penggunaan air yang tercemar untuk berbagai kegiatan sehari-hari. Disarankan kepada masyarakat di Kelurahan Makbon untuk lebih memperhatikan kondisi kualitas air tanahnya.
\end{abstract}

Kata Kunci : air, kualitas air tanah, kota sorong 


\section{PENDAHULUAN}

\section{Latar Belakang}

Kota Air merupakan salah satu kekayaan alam yang mutlak dibutuhkan oleh setiap makhluk hidup di dunia, baik manusia, hewan maupun tumbuhan. Disamping itu, air juga sangat diperlukan bagi kegiatan-kegiatan industri. Oleh karena itu, air beserta sumber-sumbernya harus dilindungi dan dijaga kelestariannya, agar pemanfaatannya dapat dipakai untuk kepentingan dan kesejahteraan rakyat. Air tanah merupakan sumber daya alam yang sangat penting bagi manusia. Menurut UU No.7 tahun 2004, air tanah adalah air yang terdapat dalam lapisan tanah atau batuan di bawah permukaan tanah. Definisi lain menyebutkan air tanah adalah sejumlah air di bawah pemukaan bumi yang dapat dikumpulkan dengan sumur-sumur, terowongan atau sistem drainase atau dengan pemompaan. Dapat juga disebut aliran yang secara alami mengalir ke permukaan tanah melalui pancaran atau rembesan. Air tanah memiliki peranan penting bagi manusia. Manusia memanfaatkan air tanah sebagai sumber air untuk kehidupan sehari-hari. Hasil Riskesdas 2010 menunjukkan bahwa jenis sumber utama air untuk seluruh keperluan rumah tangga pada umumnya menggunakan sumur gali terlindung $(27,9 \%)$ dan sumur bor/pompa $(22,2 \%)$ dan air ledeng/PAM $(19,5 \%)$.

Berdasarkan karakteristik tempat tinggal, terdapat perbedaan jenis penggunaan sumber utama air untuk keperluan rumah tangga. Di perkotaan, pada umumnya rumah tangga menggunakan sumur bor/pompa (30,3\%), sedangkan di perdesaan lebih banyak menggunakan sumur gali terlindung (29,6\%) (Riskesdas 2010). Tempat Pembuangan Akhir (TPA) sampah merupakan tempat dimana sampah mencapai tahap terakhir dalam pengelolaannya sejak mulai timbul di sumber, pengumpulan, pemindahan/pengangkutan, pengolahan dan pembuangan. TPA merupakan tempat dimana sampah diisolasi secara aman agar tidak menimbulkan gangguan terhadap lingkungan sekitarnya. Karenanya diperlukan penyediaan fasilitas dan perlakuan yang benar agar keamanan tersebut dapat dicapai dengan baik.

TPA sampah harus direncanakan dengan baik, dilihat aspek ketersediaan lahan, pembiayaan, operasional dan pemeliharaan serta dampak terhadap lingkungan. Sampah yang tidak terdekomposisi dengan baik akan menghasilkan gas dan cairan yang dikenal dengan istilah leachate(air lindi). Gas hasil dekomposisi dapat menyebabkan bau dan gangguan pernafasan bagi penduduk sekitar lokasi tersebut.

\section{Tujuan Penelitian}

Penelitian ini bertujuan untuk menganalisa kualitas air tanah di sekitar daerah TPA menurut parameter fisik dan makrobiologi.

\section{STATE OF THE ART}

Adapun penelitian terdahulu yang terkait dengan penelitian ini adalah sebagai berikut :

1. Menurut Iriani (2014) tentang Analisis Kualitas Air Tanah Bebas Di Sekitar TPA Banyuroto Desa Banyuroto Kecamatan Nanggulan Kabupaten Kulon Progo Yogyakarta menyebutkan bahwa :

a. Kualitas air tanah bebas di sekitar lokasi TPA Banyuroto pada musim kemarau secara umum memenuhi persyaratan baku mutu air minum, kecuali unsur TDS pada sampel air tanah nomor 5, 3, 6 dan unsur bakteri coliform total pada sampel air tanah nomor 3. Tingginya TDS disebabkan oleh perbedaan kadar bahan organik di tiap sampel air. Adapun tingginya bakteri coliform pada sampel nomor 3 dikarenakan lokasinya yang berdekatan dengan sumber pencemar peternakan ayam.

b. Air tanah bebas di sekitar lokasi TPA sampah sampai dengan radius $644 \mathrm{~m}$ pada elevasi yang lebih rendah dari lokasi TPA di musim kemarau masih layak dimanfaatkan sebagai air minum, kecuali unsur TDS pada sampel air tanah nomor 5, 3, 6 dan unsur bakteri coliform total pada sampel air tanah nomor 3.

2. Menurut Nur (2015) tentang Analisis Kualitas Air Tanah Di Sekitar TPA Tamangapa dengan Parameter Biologi menyebutkan hasil penelitiannya adalah : 
a. Hasil pemeriksaan kualitas air sumur di sekitar TPA Tamangapa untuk parameter biologi (Total Coliform) dan ( fecal coliform) ialah :

1. Total coliform Kualitas air tanah di sekitar TPA Tamangapa pada parameter total coliform didapat nilai Total coliform terendah yaitu 460MPN/100ml dan nilai Total coliform tertinggi yaitu 2400MPN/100ml. Terdapat 8 sampel yang telah melampaui ambang batas maksimum yang diperbolehkan menurut Kriteria Mutu Air Kelas I Berdasarkan Peraturan Pemerintah Republik Indonesia Nomor 82 Tahun 2001 tentang Pengelolaan Kualitas Air dan Pengendalian Pencemaran Air.

2. Fecal Coliform Kualitas air tanah di sekitar TPA Tamangapa pada parameter fecal coliform didapat nilai terendah yaitu 29MPN/100ml dan nilai Fecal Coliform tertinggi yaitu 115 MPN/100ml. Terdapat 3 sampel yang telah melampaui ambang batas maksimum yang diperbolehkan menurut Kriteria Mutu Air Kelas I Berdasarkan Peraturan Pemerintah Republik Indonesia Nomor 82 Tahun 2001 tentang Pengelolaan Kualitas Air dan Pengendalian Pencemaran Air.

b. Berdasarkan hasil analisis data, tidak ada pengaruh jarak TPA Tamangapa terhadap jumlah bakteri didalam air tanah. Akan tetapi keberadaan TPA sangat mempengaruhi jumlah bakteri didalam air tanah.

c. Berdasarkan hasil analisis data, kedalaman sumur sangat berpengaruh terhadap jumlah bakteri total coliform dan fecal coliform, semakin dalam sumur semakin rendah bakterinya.

d. Dengan menggunakan Metode Storet dalam mengidentifikasi tingkat pencemar air sumur di sekitar TPA Tamangapa diperoleh rata-rata hasil analisis dari lokasi titik sumur yaitu -5,4 termasuk Cemar Ringan.

3. Menurut Fajarini (2017) Analisis Kualitas Air Tanah Dangkal Untuk Keperluan Air Minum Di Desa Pematang Kecematan Kalianda Kabupaten Lampung Selatan menyebutkan berdasarkan hasil penelitian di lapangan dan uji laboratorium UPTD Provinsi Lampung terhadap enam sampel air tanah dangkal (sumur) di Desa Pematang Kecamtan Kalianda Kabupaten Lampung Selatan Tahun 2017 maka hasil penelitian menunjukkan bahwa air tanah dangkal (sumur) yang digunakan masyarakat Desa Pematang Kecamatan Kalianda Kabupaten Lampung Selatan ditinjau dari sifat fisiknya hasil penelitian menunjukkan bahwa air tanah dangkal (sumur) memenuhi syarat karena kondisi air terlihat bening, tidak berwarna, tidak berbau, tidak berasa, dan berada pada suhu normal. Hanya pada sampel II dan V air berasa asam hal ini diduga terjadi secara alamiah yaitu merupakan hasil pelapukan batuan induk dari tanah, mengingat lokasi pengambilan sampel tidak ada industri. Sifat kimia air tanah dangkal (sumur) juga memenuhi syarat karena kandungan besi $(\mathrm{Fe})$, kesadahan ( $\mathrm{CaCO} 3)$, kandungan klorida $(\mathrm{Cl})$, kandungan sulfat (SO4), dan kandungan zat padat tersuspensi berada di bawah ambang batas standar baku mutu air.

\section{METODE}

\section{Tahapan Penelitian}

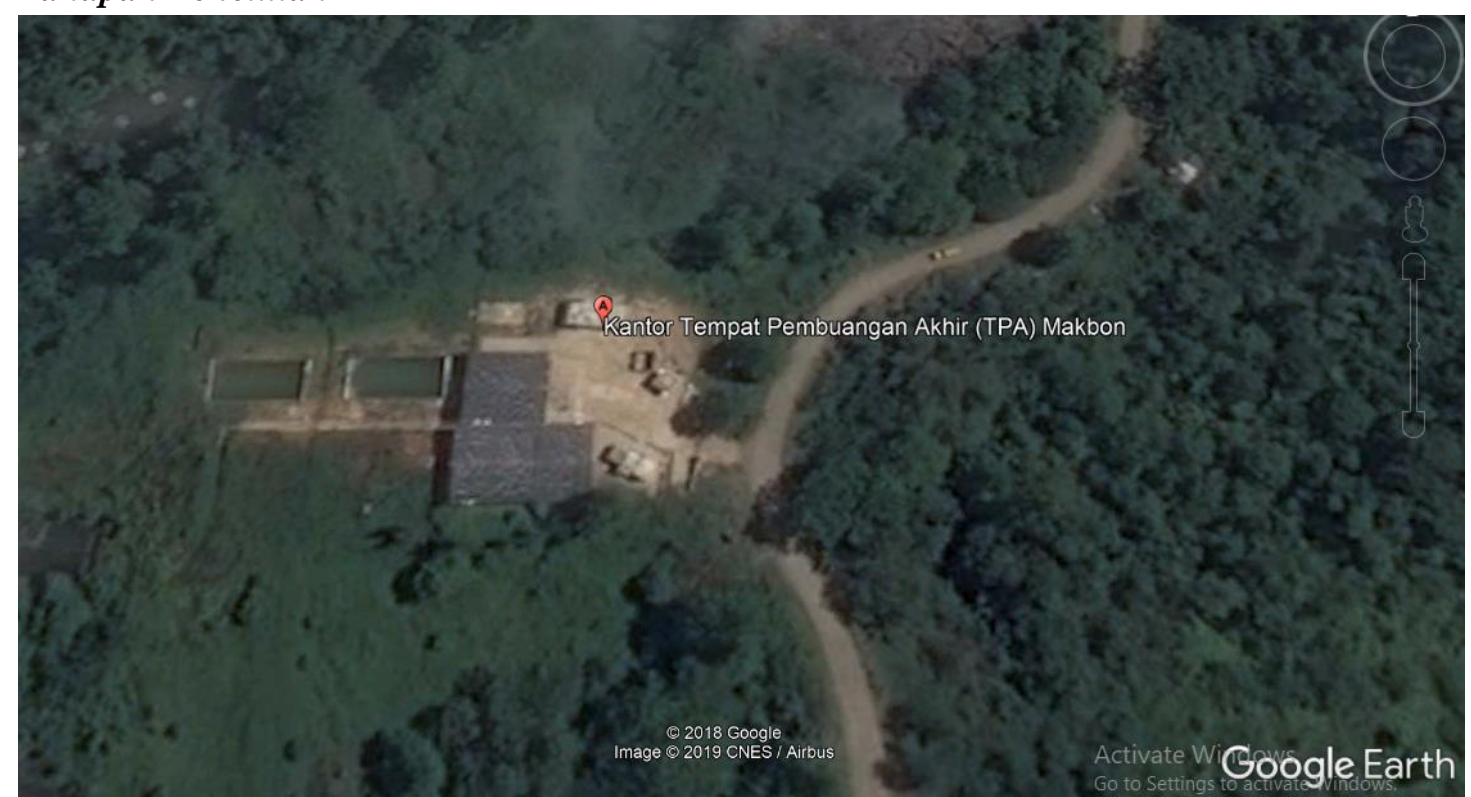

Tahapan penelitian yang digunakan adalah sebagai berikut :

1. Melakukan pengamatan langsung terhadap aliran sungai di wilayah TPA Makbon Kota Sorong 
2. Mengolah data dari hasil yang telah di dapatkan pada saat melakukan pengamatan langsung .

3. Mengidentifikasi dan menganalisa kualitas air tanah di muara sungai TPA Makbon Kota Sorong.

Semua metode penulisan dan analisa dalam artikel ilmiah ini merujuk pada panduan penulisan tugas akhir Fakultas Teknik Universitas Muhammadiyah Sorong tahun 2014 (Pristianto, Amri, \& Rusdi, 2014).

\section{REFERENSI}

1. Iriani, S (2014) Analisis Kualitas Air Tanah Bebas Di Sekitar TPA Banyuroto Desa Banyuroto Kecamatan Nanggulan Kabupaten Kulon Progo Yogyakarta

2. Nur, F (2015) Analisis Kualitas Air Tanah Di Sekitar TPA Tamangapa dengan Parameter Biologi

3. Fajarini (2017) Analisis Kualitas Air Tanah Dangkal Untuk Keperluan Air Minum Di Desa Pematang Kecematan Kalianda Kabupaten Lampung Selatan

4. Pristianto, H., Amri, I., \& Rusdi, A. (2014, May 9). Pedoman Penulisan Tugas Akhir Fakultas Teknik Universitas Muhammadiyah Sorong 2014. http://doi.org/10.17605/OSF.IO/4VTJM. 